\title{
Isolation, Identification and Determination of the Prevalence of Mycobacterium tuberculosis Complex among People Living with HIV in Kisumu County, Kenya
}

\author{
Maryanne Betsy Usagi ${ }^{1}$, Gilbert Abura Odilla ${ }^{2}$, John Muthini Maingi ${ }^{1}$, Anthony Kebira ${ }^{1}$ \\ ${ }^{1}$ Department of Microbiology, School of Science, Kenyatta University, Nairobi, Kenya \\ ${ }^{2}$ Department of Education, Faculty of Education and Resources Development, Chuka University, Chuka, Kenya
}

Email address:

usagibetsy@gmail.com (M. B. Usagi),gilbura@yahoo.com (G. A. Odilla)

\section{To cite this article:}

Maryanne Betsy Usagi, Gilbert Abura Odilla, John Muthini Maingi, Anthony Kebira. Isolation, Identification and Determination of the Prevalence of Mycobacterium tuberculosis Complex among People Living with HIV in Kisumu County, Kenya. Science Journal of Public Health. Vol. 4, No. 4, 2016, pp. 359-365. doi: 10.11648/j.sjph.20160404.24

Received: June 15, 2016; Accepted: July 12, 2016; Published: July 28, 2016

\begin{abstract}
Mycobacterium tuberculosis complex are important pathogens to man and causative agents of tuberculosis. Tuberculosis is one of the diseases that continue to be a public health concern in the world. Earlier, tuberculosis was considered controlled, but with emergence of HIV and AIDS, the disease has been exacerbated, with the highest incidences being in subSaharan Africa. Kenya ranks $15^{\text {th }}$ and $5^{\text {th }}$ in the World and Africa respectively. The World Health Organization indicates that there were 300 TB cases per 100,000 people in 2011. Information on the identity of the Mycobacterium tuberculosis complex and the prevalence of pulmonary tuberculosis in HIV positive patients seeking treatment in Kisumu County is limited. In this study, we isolated and identified the Mycobacterium tuberculosis complex and also determined the prevalence of tuberculosis in HIV patients seeking treatment in Kisumu County. A cross-sectional study was conducted between December 2013 and June 2014. The study engaged, 379 HIV positive patients suspected of TB infection who gave sputum samples. The sputum samples were then decontaminated, concentrated, liquefied and neutralized before being cultured in liquid media using MGIT 960 tubes. The culture positive MGIT tubes were sub cultured in Brain Heart Infusion Agar (BHIA) before microscopic examination of the culture using ZN smear for Acid Fast Bacilli and identified using Genotype MTBC. In the study, 130 (34.3\%) of the 379 suspected TB patients were diagnosed positive for pulmonary TB by MGIT culture. A significantly greater number of males were diagnosed with pulmonary tuberculosis compared to females $\left(57.7 \%\right.$ and $42.3 \%$ respectively; $\chi^{2}=$ $1.0342, \mathrm{df}=1 \mathrm{P}<0.05)$. Further, the study revealed that TB prevalence decreased steadily with age, with the youths being at greater risk of becoming active patients. In the age category of $26-35$ years, prevalence was $36.92 \%$ while, for age category above 55 years it was $6.15 \%$. Based on the results, the etiological agent of tuberculosis in Kisumu County is Mycobacterium tuberculosis, the prevalence of infection was higher in males than in females and the prevalence rate to infection was highest among the youth. There is need for rapid and accurate diagnosis of active TB particularly in HIV-positive patients. Also, TB awareness and control programme should mainly be directed towards the youths by the all the stakeholders in the Public Health sector.
\end{abstract}

Keywords: Determination, Mycobacterium Tuberculosis Complex, Isolation, Identification, Prevalence

\section{Introduction}

Mycobacterium tuberculosis complex are rod shaped aerobic bacteria that do not form spores [4]. These microorganisms are significant pathogens of humans since they cause tuberculosis. Tuberculosis is caused by different species in the Mycobacterium tuberculosis complex family.
According to [9], TB can be caused by Mycobacterium tuberculosis, M. bovis or M. africanum. The existence of different species has posed a critical challenge in the control and management of TB. This is due to the inability to accurately and rapidly diagnose active TB in the Southern Countries, especially in people living with HIV [25]. Currently, tuberculosis disease is the most threatening 
infection globally [21]. According to [26], a third of the world's population is infected with the TB bacillus.

Globally, TB incidence has been on the increase since the early 1990's [26]. It is estimated that the disease kills approximately eight thousand people a day which translates to 2-3 million people each year [25]. This death toll is the world's second highest for an infectious disease, after HIV/AIDS [24]. HIV and TB form a deadly combination, since each speeds the other's progress. People living with HIV have a weakened immune system that makes them vulnerable to the devastating effects of TB [24]. In 2009, The Indian Central TB Division [12] reported that India had 3.5 million HIV patients of whom about 1.8 million were also infected with tuberculosis. According to this report, diagnosis of TB in HIV patients is more difficult than in people without HIV infection, thus the need for proper scrutiny. In SubSaharan Africa, TB is the major cause of mortality among people living with HIV [28].

In Kenya, TB is the most common opportunistic infection affecting people living with HIV and contributes to the high morbidity and mortality rates [11]. Kenya has witnessed a rise in new TB cases since the early 1990's, recording a nine fold increase of reported TB cases [13]. Concurrent HIV epidemic is the major factor responsible for the heavy TB disease burden in Kenya [10]. In 2009 HIV sero-prevalence among TB patients was at $44 \%$ [13]. Further, there exists inability to accurately and rapidly diagnose active TB, hence posing a major hindrance in the control and management of tuberculosis [13]. Most hospitals in Kenya diagnose TB by smear microscopy which fails to identify about $30-40 \%$ of active TB cases [13]. Use of Smear Microscopy method is less reliable especially when used in populations with high rates of HIV [20]. The thirty to forty percent of active TB cases that go undetected could be the cause of rapid increase of TB which is becoming a public health concern.

According to [25], patients with smear negative pulmonary TB accounted for about $17 \%$ TB transmission. This means that microscopic diagnosis does not detect a significant proportion of TB cases. The method of diagnosis of TB used in most hospitals does not determine drug sensitivity [25] and thus poses a challenge in the proper treatment of tuberculosis. Unsuitable treatment and poor patient compliance to treatment have led to drug resistance [21]. A definitive diagnosis can best be made by culturing Mycobacterium tuberculosis complex isolates from specimens of patients, use of GeneXpert or by use of PCR [25].

Data on the prevalence of $M$. tuberculosis among people living with HIV is not available in most areas of Kenya. The statistics on HIV/AIDS in Kisumu County is quite alarming especially with prevalence rates of $15 \%$ which is higher than the national average of $6.7 \%$ according to [14]. Further, regions close to the beaches in Kisumu County have been found to have even higher HIV prevalence of $26 \%$ [14]. Despite this worrying phenomenon, the information available on the identity and prevalence of $M$. tuberculosis is generalized and scanty. [22] documents that in the developing world, much emphasis is put on treatment and curbing spread rather than on identification and prevalence. This study therefore was carried out to identify the species and determine the prevalence of $M$. tuberculosis complex circulating in people living with HIV in Kisumu County.

\section{Materials and Methods}

\subsection{Study Site}

This study was carried out at KEMRI/CDC Laboratories on sputum samples collected by KEMRI/CDC from health facilities within Kisumu County. The County covers an area of $2085.9 \mathrm{~km}^{2}$ and has a population of 968,909 . It neighbors Vihiga County to the North, Nandi County to the North East, Kericho County to the East, Nyamira County to the South, Homa Bay County to the South West and Siaya County to the West (Fig. 1). The County has one provincial referral hospital, three district hospitals, five sub-district hospitals, fifty three dispensaries and six health centers.

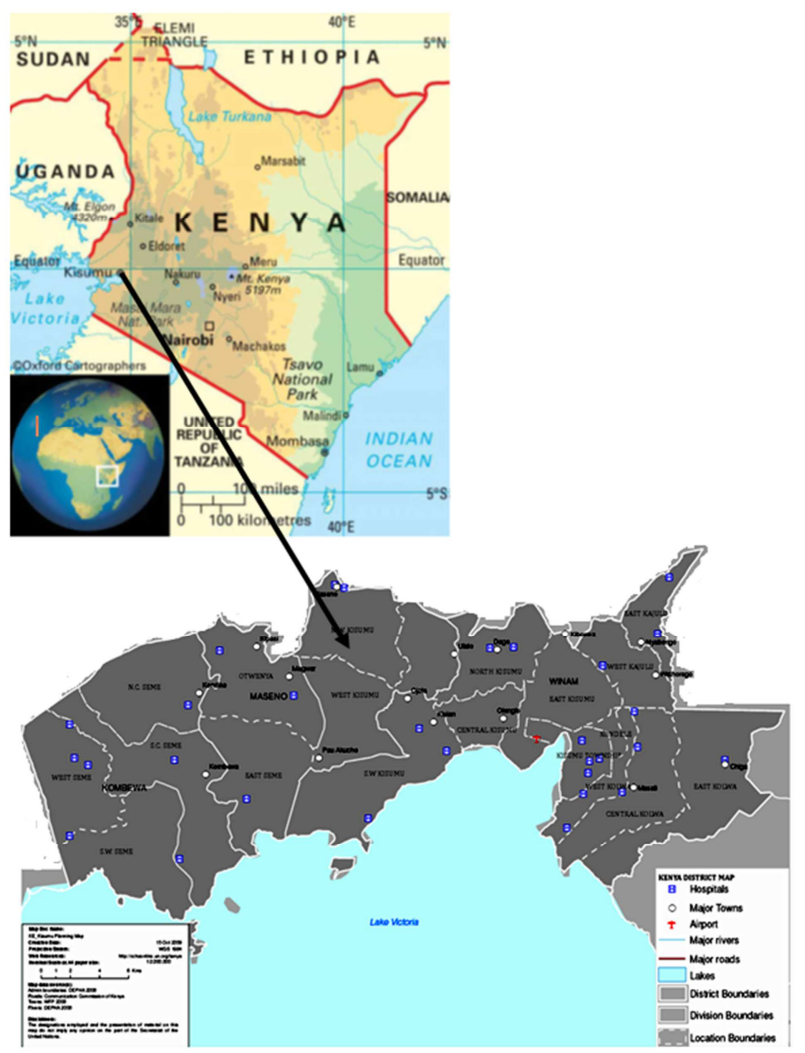

Figure 1. Map of Kisumu County (Oxford Cartographers).

\subsection{Study Population}

The study was a cross-sectional design on 379 people living with HIV, 15 years and above who presented symptoms of pulmonary tuberculosis in health facilities in Kisumu County. The sample size was determined using the [6] formula. Children below fifteen years of age with HIV presenting with symptoms for PTB were not included because they are not able to expectorate and provide specimen [5]. HIV patients presenting with symptoms for extra pulmonary tuberculosis and HIV negative patients 
presenting with symptoms for pulmonary tuberculosis were also not included in the study.

\subsection{Microbial Culture}

Three sputum samples collected per patient were put in a cool box and transported to the laboratory at KEMRI-CDC for analysis. At the laboratory, the sputum samples were macroscopically examined for adequate quantity and contained mucoid or mucopurulent material. Decontamination and concentration of the specimens, was carried out in a biosafety cabinet at a Biosafety Level 3 (BSL 3) Laboratory at KEMRI-CDC. Briefly, all specimens were transferred into $50 \mathrm{ml}$ falcon tubes which were staggered in racks to prevent cross contamination. An equal amount of $\mathrm{N}$ Acetyl-L-Cysteine-Sodium hydroxide (NALC-NaOH) solution was added at a time to each specimen tube. The tubes were rotated and inverted to ensure that the mixture coated the entire interior surface and then vortexed for 15 seconds [22]. To the specimens that were too mucoid to liquefy, a small amount of NALC powder (30 grams) was added to each directly and vortexed, then allowed to stand for 15 minutes to allow adequate liquefaction. Neutralization was carried out by slowly adding a phosphate buffer $\mathrm{pH} 6.8$ into the specimen to the $50 \mathrm{ml}$ mark and the surface of the tubes wiped with disinfectant $(5 \%$ phenol). The tubes were inverted several times to mix thoroughly.

The tubes were then loaded into aerosol-free centrifuge cups and centrifuged at $3000 \mathrm{x}$ g for 15-20 minutes to concentrate the specimen. The supernatant was discarded and the sediment re-suspended by adding 1-2 $\mathrm{ml}$ of phosphate buffer $\mathrm{pH}$ 6.8. The tube contents were gently mixed and the suspension used for preparation of smears and microbiological processes [22].

Microscopic examination for acid-fast bacilli (AFB) was carried out on each sputum sample after staining each slide with the standard Zeihl Neelsen (ZN) staining method for M. tuberculosis [22]. The AFB smears appeared either as serpentine cording, clumps or singly. Positive (M. fortuitum) and negative (E. coli) controls were included with each batch of slides for staining [23].

MGIT culture inoculation was carried out by carefully adding about $0.5 \mathrm{ml}$ of the concentrated specimen suspension to the prepared $\mathrm{BBL}^{\mathrm{TM}}$ mycobacteria growth indicator tube using a pipette. The MGIT 960 tubes (Becton Dickinson and Co., Cockerysville, Md.) were tightly recapped and the contents mixed thoroughly. The inoculated tubes were left at room temperature for 30 minutes before loading into the MGIT system following manufacturer's instructions for incubation. The tubes were thereafter incubated at $37^{\circ} \mathrm{C}$ and monitored for increasing fluorescence. The incubation duration was 42 days until the culture flagged positive. Positive and negative controls were included with each set of specimens. The growth of Mycobacterium tuberculosis obtained was used for sensitivity testing [22].

The inoculated cultures were then examined and identified according to the MGIT Procedure Manual [22]. All culture positive MGIT 960 tubes were then subjected to tests to rule out contamination before testing for drug sensitivity.

Specimen in the MGIT 960 tubes found to be positive for Mycobacteria were sub-cultured in brain heart infusion agar (BHIA). These sub-cultures were incubated in carbon (IV) oxide incubators for 48 hours. The plates examined after every 24 hours to rule out bacterial false positive. For quality control, an empty BHIA was incubated on the carbon (IV) oxide incubator for 48 hours alongside another BHIA with E. coli and $S$. aureus. The cultures were considered positive after they were confirmed to show acid fast bacteria by $\mathrm{ZN}$ microscopy and negative growth on BHIA. ZN positive and BHIA positive tubes were also considered but after re-decontamination. They were all then identified using Genotype MTBC. Microscopic examination was carried out using the Ziehl-Neelsen staining procedure described earlier on each sample.

Genotyping of Mycobacterium tuberculosis complex was based on the DNA-STRIP technology according to the manufacturer's instructions (Hain Life science $\mathrm{GmbH}$, Nehren, Germany). Thereafter, DNA was extracted from bacteria cultured in MGIT 960 media and then one milliliter of bacteria growth was spanned into a pellet at $10,000 \mathrm{x} \mathrm{g}$ for 15 minutes in a standard table top centrifuge. The supernatant formed was discarded and the bacteria re-suspended in 100-300 $\mu \mathrm{l}$ of water by vortexing. The bacteria were then incubated for 20 minutes at $95^{\circ} \mathrm{C}$ in a water bath. The bacteria were again incubated in an ultrasonic bath and once again span at full speed for 5 minutes. Five microliters of the supernatant was placed in new labelled tube and used for amplification.

Standard PCR Amplification was done using mixes A and $\mathrm{B}$ containing polymerase and primers. The resultant products from the PCR were subjected to further identification on strips as described by [22].

\subsection{Data Analysis}

Data was analyzed using both descriptive and inferential statistics with help of STATA version-10. Descriptive statistics was used to summarize data and chi- square $\left(\chi^{2}\right)$ test used to investigate differences between sputum culture positive and negative.

\section{Results}

\subsection{Baseline Characteristics of Study Participants}

Out of the 379 pulmonary TB suspects enrolled, 205 $(54.1 \%)$ were males while 174 (45.9\%) were females. Their ages ranged from 15 to 88 years although the mean age was 35.5 years with a standard deviation of 11.9 . One hundred and thirty $(34.3 \%)$ of the three hundred and seventy nine pulmonary TB suspects were diagnosed positive for tuberculosis by culture. Of the 130 culture positive, 122 (93.9\%) were smear-positive and $8(6.1 \%)$ smear-negative (Table 1). Male TB patients accounted for $57.7 \%$ (75) of the patients while the females' were $42.3 \%$ (55). There was no significant difference between the culture positive and culture negative groups in terms of gender and age distribution ( $p$ value of 0.309) (see Table 1). 
Table 1. Baseline characteristics of participants enrolled in the study and their association with culture outcome as analyzed by the $\chi^{2}$ test.

\begin{tabular}{llll}
\hline characteristics & Positive sputum culture n (\%) & Negative sputum culture n (\%) & P-value \\
\hline Gender & & & \\
Male & $75(57.7)$ & $130(52.2)$ \\
Female & $55(42.3)$ & $119(47.8)$ \\
Sputum microscopy & & \\
Smear-positive & $122(93.9)$ & $27(10.8)$ \\
Smear-negative & $8(6.1)$ & $222(89.2)$ \\
Age Categories (yrs) & & \\
25 and below & $75(19.8)$ & \\
$26-35$ & $135(35.6)$ & \\
$36-45$ & $102(26.9)$ & \\
$46-55$ & $45(11.9)$ & \\
Above 55 & $22(5.8)$ & \\
\hline
\end{tabular}

$\mathrm{n}=$ frequency, $\%=$ percentage

\subsection{Isolation and Identification of Mycobacterium Tuberculosis Complex}

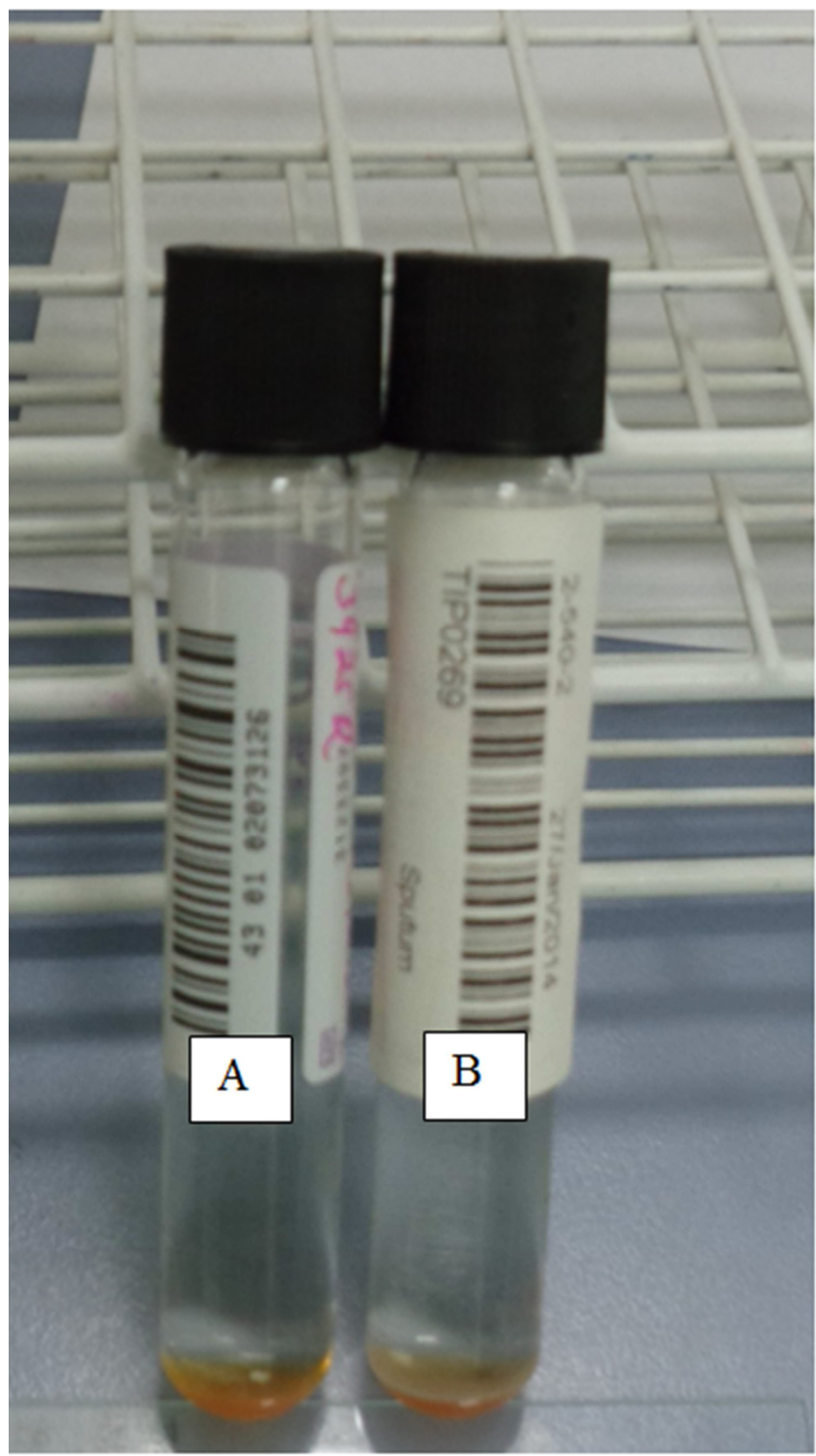

Figure 2. Mycobacterium tuberculosis MGIT tubes. A; negative, B; positive.
Growth of MTBC (culture positive) was observed in 130 isolates accounting for $34.3 \%$ of the 379 samples (Plate 1). The growth of MTBC in MGIT culture provided a definite diagnosis for tuberculosis (Table 2). AFB smear (ZN smear) was again performed on all positive MGIT tubes to confirm the presence of TB bacteria (Plate 2). From the results obtained, 249 isolates were culture negative and were thus excluded from further analysis.

Molecular genetic assay performed on the 130 culture positive isolates provided rapid identification of the MTBC species causing tuberculosis (Fig. 2). The determination of species was made on the basis of detection of bands with the help of an interpretation sheet. The results obtained indicated that Mycobacterium tuberculosis was the only Mycobacterium species causing TB in all the 130 isolates. No Mycobacterium bovis or Mycobacterium africanum were identified in the study. Therefore, Mycobacterium tuberculosisis is the Mycobacterium species circulating in people living with HIV and infected with $\mathrm{TB}$ in Kisumu County.

Table 2. Distribution of sputum samples collected.

\begin{tabular}{lllll}
\hline MGIT & $\mathbf{n}$ & $\mathbf{\%}$ & Genotype MTBC & $\mathbf{n}$ \\
\hline Positive & 130 & 34.3 & $\begin{array}{l}\text { M. tuberculosis } \\
\text { M. Bovis }\end{array}$ & 130 \\
Negative & 249 & 65.7 & M. africanum & 0 \\
Totals & 379 & 100 & & 0 \\
\hline
\end{tabular}

$\mathrm{n}=$ frequency, $\%=$ percentage

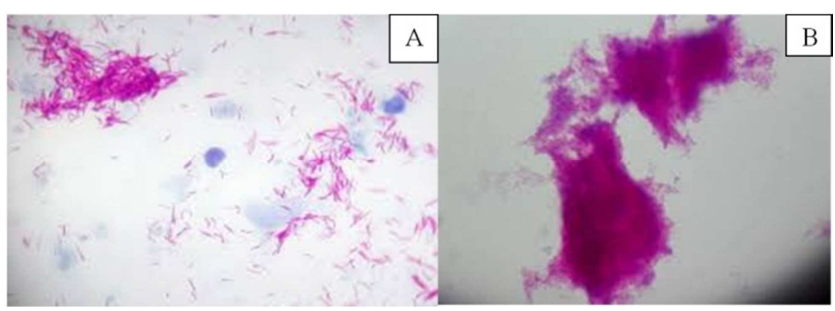

A; singly,

B; clumps

Figure 3. Microscopy morphology of Mycobacterium tuberculosis smears. 


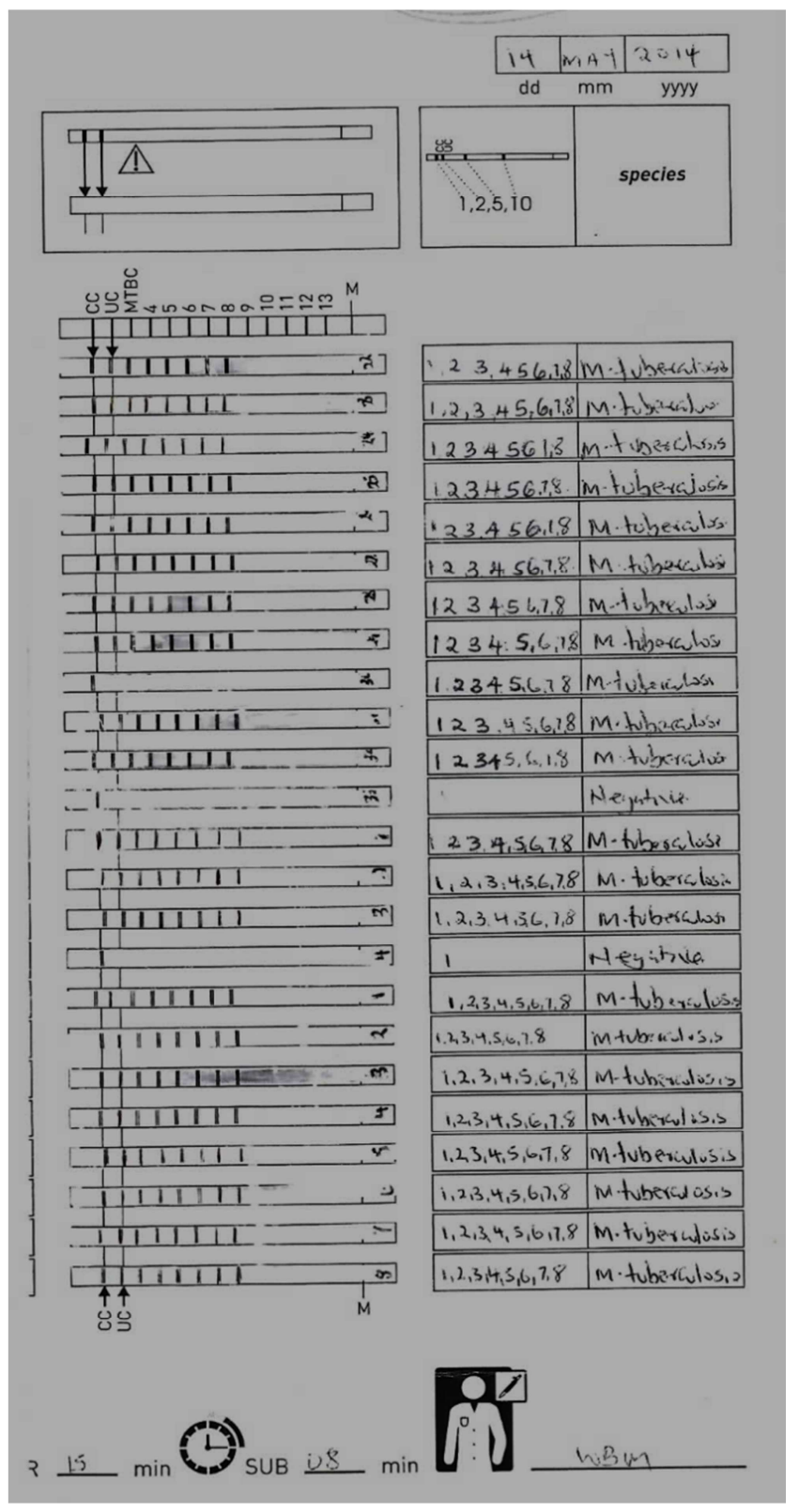

Figure 4. Assay patterns of Mycobacterium tuberculosis species identified in Kisumu County.

\section{Discussions}

Growth of Mycobacterium tuberculosis complex was observed with sputa of 130 of the 379 suspected TB patients (Table 2). The identification of the isolates by genotype MTBC revealed Mycobacterium tuberculosis as the only Mycobacterium specie causing pulmonary tuberculosis for the samples collected from Kisumu County. This bacterium has also been detected as the cause of tuberculosis in previous studies carried out in Uganda, Ethiopia and Cameroon [1, 2, 3]. Tuberculosis is caused by different species in the Mycobacterium tuberculosis complex family. According to [10] TB could be caused by Mycobacterium tuberculosis, Mycobacterium bovis or Mycobacterium africanum. [16] documents that Mycobacterium africanum is a species of Mycobacterium that is most commonly found in

West Africa. [7] also documents that Mycobacterium bovis causes TB in cattle but occasionally causes TB in humans. It is transmitted to humans through infected milk that is unpasteurized.

This study also reveals a significantly greater number of males diagnosed with pulmonary tuberculosis compared to females $\left(57.7 \%\right.$ and $42.3 \%$ respectively; $\chi^{2}=1.0342, \mathrm{df}=1$ $\mathrm{P}<0.05)$. Similar observations were also made in previous studies carried out in Cameroon and Nairobi [2, 15 and 17]. [9] documents that males were 1.4 times more likely to have TB than women. This concurs with world health report [24], which indicates that most of TB cases and deaths occur among men. This could be attributed to the behavioral factors such as smoking which is a predisposing factor to TB with more males being smokers than females [8]. In addition, alcohol consumption, malnutrition and delay in seeking medical treatment especially by males are factors associated with higher numbers of males than females with TB $[19,8]$.

Further, the study revealed that, TB prevalence decreased steadily with age, with the youths being at greater risk of becoming active patients. In age category $26-35$ years, prevalence was $36.92 \%$ and $6.15 \%$ for age category above 55 years. This agrees with study carried out in Cameroon. In the study, [2] reported that patients' age distribution showed a steady decline in age-specific prevalence from $30.58 \%$ in age group $15-29$ years to $15.51 \%$ in the age group above 60 years. Moreover, $[10,11]$ documents that the youths had the highest TB notification. In Nyanza, this age group was socioeconomically more active and also had the highest HIV prevalence rates [14].

\section{Conclusion}

The study confirmed that the etiological agent of tuberculosis for affected HIV patients in Kisumu County is Mycobacterium tuberculosis. Further, the study revealed that the prevalence of infection was higher in males than in females. Gender was also found to be a statistically significant determinant of TB prevalence at the study area. The prevalence rate of TB infection was higher in the age category of 26-35 years compared to age category above 55 years.

\section{Recommendations}

There is need for rapid and accurate diagnosis of active TB particularly in HIV positive patients. Also, TB awareness and control programme should mainly be directed towards the youths by the all the stakeholders of Public Health in Kisumu County.

\section{Abbreviations \\ AFB \\ AIDS \\ AM-A \\ Acid fast bacteria \\ Acquired Immunodeficiency Syndrome Amplification mix A}




$\begin{array}{ll}\text { AM-B } & \text { Amplification mix B } \\ \text { BHIA } & \text { Brain heart infusion agar } \\ \text { BSL3 } & \text { Biosafety laboratory level 3 } \\ \text { CDC } & \text { Centers for Disease Control and Prevention } \\ \text { CFU } & \text { Colony forming units } \\ \text { DNA } & \text { Deoxyribonucleic acid } \\ \text { DOTS } & \text { Directly Observed Treatment Short course } \\ \text { DST } & \text { Drug sensitivity test } \\ \text { EPTB } & \text { Extra-pulmonary Tuberculosis } \\ \text { ETH Ethambutol } \\ \text { Genotype } & \text { Test system for the differentiation of } \\ \text { MTBC } & \text { Mycobacterium } \\ \text { Tuberculosis } & \text { Complex } \\ \text { GC } & \text { Growth control } \\ \text { HIV } & \text { Human Immunodeficiency Virus } \\ \text { INH } & \text { Isoniazid } \\ \text { JOOTRH } & \text { Jaramogi Oginga Odinga Teaching and } \\ \text { KEMRI } & \text { Referral Hospital } \\ \text { MDGs } & \text { Kenya Medical Research Institute } \\ \text { MDR-TB } & \text { Millennium Development Goals } \\ \text { MGIT } & \text { Multidrug Resistant Tuberculosis } \\ \text { MOTT } & \text { Mycobacteria Growth Indicator } \\ \text { MoDP } & \text { Mycobacteria other than M. tuberculosis } \\ \text { MoH } & \text { Ministry of Devolution and Planning } \\ \text { MoPHS } & \text { Ministry of Health } \\ \text { MTBC } & \text { Ministry of Public Health and Sanitation } \\ \text { NACL } & \text { Mycobacterium tuberculosis complex } \\ \text { NaOH } & \text { N-Acetyl-L-Cysteine } \\ \text { NASCOP } & \text { Sodium Hydroxide } \\ \text { PCR } & \text { National AIDS and STI Control Programme } \\ \text { PTB } & \text { Polymerase Chain Reaction } \\ \text { RIF } & \text { Pulmonary tuberculosis } \\ \text { SIRE } & \text { Rifampicin } \\ \text { STR } & \text { Streptomycin, Isoniazid, Rifampicin, } \\ \text { TB } & \text { Ethambutol } \\ \text { WHO } & \text { Streptomycin } \\ \text { XDR-TB } & \text { Tuberculosis } \\ \text { XPERT MTB } & \text { World Health Organization } \\ \text { ZN } & \text { Ziehl-Neelsen } \\ & \end{array}$

\section{Competing Interests}

The authors would like to declare that there is no competing interests.

\section{Acknowledgements}

We are totally indebted to God for the success of this study. We are particularly grateful to Dr. Kevin Cain (TB Branch Chief, KEMRI/CDC), Mr. Albert Okumu (TB Laboratory Director) and Ms. Janet Agaya for granting us permission to use the KEMRI/CDC TB Laboratories. We would also like to thank Dr. Jackson Kioko, the head of Leprosy, Tuberculosis and Lung Disease Unit for granting us the permission to use samples from the Ministry of Health. The authors also appreciate the immense contribution of the entire KEMRI/CDC TB Laboratory staff. We are also grateful for the financial and moral support from our family members and friends.

\section{References}

[1] Adane, K., Ameni, G., Bekele, S., Abede, M. and Aseffa, A. (2015). Prevalence and drug resistance profile of Mycobacterium tuberculosis isolated from pulmonary tuberculosis patients attending two public hospitals in East Gojjam zone, Northwest Ethiopia. Biomed Central Public Health, 15: 1933-1939.

[2] Jean-Paul Assam-Assam 1, Veronique B Penlap, Fidelis Cho-Ngwa 1, Jean-Claude Tedom, Irene Ane-Anyangwe 1 and Vincent P Titanji. (2011). Mycobacterium tuberculosis complex drug resistance pattern and identification of species causing tuberculosis in the West and Centre regions of Cameroon. Biomed Central Public Health, 1471-2334-11-94

[3] Asiimwe, B. B., Koivula, T., Källenius, G., Huard, R. C., Ghebremichael, S. Asiimwe, J. and Joloba, M. L. (2008). Mycobacterium tuberculosis Uganda genotype is the predominant cause of TB in Kampala, Uganda. International Journal of Tuberculosis and Lung Disease, 12 (4): 386-91

[4] Brooks, G. F., Carrol, C. K., Butel, J. S. and Morse, S. A. (2007). Medical microbiology $24^{\text {th }}$ ed. McGraw Hill, New York.

[5] Chakaya, J. M. (2005). National Leprosy and Tuberculosis Programme. What the health worker needs to know. Nairobi, Government printers.

[6] Fisher, A. A., Liang, J. E., Stoeckel, J. E and Townsend J. J. (1998). Hand book for family planning operations research designs $2^{\text {nd }}$ ed. Population council, New York USA.

[7] Grange, J. M., Malcolm, D. Y. and Kantor I. N., (1996). Guidelines for speciation within the Mycobacterium tuberculosis complex $2^{\text {nd }}$ ed. WHO. Available on line (http://whqlibdoc.who.int/hq/1996/WHO EMC ZOO 96pdf). Accessed August 2014.

[8] Lonnroth, K., Juramillo, E., Williams, B., Dye, C., Raviglione, M. (2009). Drivers of tuberculosis epidemics. The role of risk factors and social determinants. International Journal of Tuberculosis and Lung Diseases 8: 245357.http://www.sciencedirect.com/science/article/pii/SO27779 53609002111. Accessed August 2014.

[9] Ministry of Health. (2010). National Leprosy Tuberculosis annual report. Government Printers, Nairobi.

[10] Ministry of Health of Kenya (MoH) (2005). National Leprosy Tuberculosis Programme. TB management guidelines. Government printers, Nairobi.

[11] Ministry of Health (MoH) (2003). National Leprosy Tuberculosis Programme. Annual report. Government printers, Nairobi.

[12] Ministry of health and family welfare (2009). Mycobacterium tuberculosis culture and drug susceptibility testing report. Government of India.

[13] Ministry of Public Health and Sanitation. (2012). TB Control. Government Printers. Nairobi.

[14] National AIDS and STI control Programme (NASCOP) Kenya (2014). Kenya AIDS Indicator Survey: Final Report. Nairobi, NASCOP. 
[15] Ndung'u, P., Kariuki, S., Ng'ang'a, Z. and Revathi, G. (2012). Resistance patterns of Mycobacterium tuberculosis isolates from pulmonary tuberculosis patients in Nairobi. Journal of Infection in Developing Countries, 6 (1): 33-39

[16] Niemann, S., Kubica, T., Bange, F. C., Adjei, O., Brown, E. N., Chinbuah, M. A., Diel, R., Gyapong, J., Horstmnn, R. D, Joloba, M. L., Meyer, C. G., Mugerwa, R. D., Okerwa, A., Osei, I., Owusu-Darbo, E., Schwander, S. K. and RuschGerdes, S. (2004). The species of Mycobacterium africanum in the light of new molecular markers. Journal of Clinical Microbiology. 42 (9) 3958-3662.

[17] Nyangau, L. O., Amukoye, E. and Ng'ang'a, Z. (2015). Determining fist line anti- tuberculosis drug resistance among new and re-treatment tuberculosis HIV infected patients, Nairobi Kenya. International Journal of Sciences, 19: (20) 426-437.

[18] Peeling, R. (2008). Tuberculosis Diagnostics evaluation 2 TDR Research publications 81. Available on line (www.who.int $/ \mathrm{tdr} / \mathrm{svc} /$ publication/tdr-research.) Accessed June 2014.

[19] Rajeswari, R., Chandrasekaran, V., Suhedev, M., Sivasubramaniam, S., Sudha, G. and Rehu, G. (2002). Factors associated with patient and health system delays in diagnosis of tuberculosis in South India. International Journal of Tuberculosis and Lung Disease. 6: 789-795.

[20] Sanchez-Padilla, E., Ardizzoni, E., Sauvageot, D., Ahoua, L., Martin, A., Varaine, F., Adatu-Engwau, F., Akeche, G., Salaniponi, F. and Bonnet, M. (2013). Multidrug and Isoniazid resistant tuberculosis in three high HIV burden African regions. International Journal of Tuberculosis and Lung Diseases. 17 (8): 1036-1042.

[21] Shinghal N., Prashant, S., Manish, K., Beenu J. and Deepa B. (2012). Analysis of intracellular Expressed Proteins of Mycobacterium tuberculosis Clinical Isolates. Proteome Science 10: 1186/1477-5956-10-14. Available on line (http:/www.proteomesci.com/content/10/1/14). Accessed July 2024.

[22] Siddiqi, S. H and Rusch-Gerdes, S. (2006). MGIT Procedure Manual. Foundation for Innovative new diagnostics. Available on line (http://www.finddiagnostics.org/export/..../pdfs/mgitmanual-nov.2006.pdf)

[23] World Health Organization (2015). Global Tuberculosis Report. $20^{\text {th }}$ Edition. Geneva.

[24] World Health Organization (2013). Global TB Report. TB/HIV fact sheet No. 104 Revised, Geneva.

[25] World Health Organization (2012). Tuberculosis Diagnostic Technology Landscape. Available on line (www.unitaid@who.int.) accessed March 2015.

[26] World Health Organization (2005). TB/HIV Fact Sheet No. 104. Geneva.

[27] World Health Organization (2004). Interim Policy on Collaborative TB/HIV Activities. WHO/HTM/TB/2004.330 and $\mathrm{WHO} / \mathrm{HIV} / 2004.01 .2004$.

[28] World Health Organization (2004). TB/HIV: A Clinical Manual $2^{\text {nd }}$ ed. Geneva. 